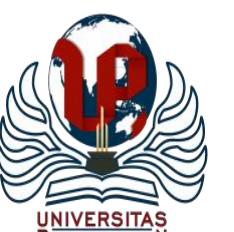

Jurnal Abdidas Volume 2 Nomor 5 Tahun 2021 Halaman 1140 - 1144

JURNAL ABDIDAS

http://abdidas.org/index.php/abdidas

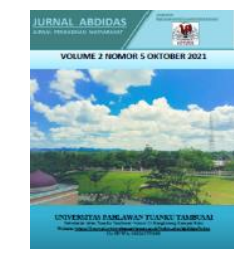

\title{
Media Pembelajaran Screen Recording dari Powerpoint dalam Pembelajaran Jarak Jauh
}

\author{
Elisabeth Margareta ${ }^{1 凶}$, Yosefin Panjaitan ${ }^{2}$ \\ Pendidikan Ekonomi, Universitas HKBP Nommensen Pematangsiantar, Indonesia ${ }^{1,2}$ \\ E-mail : elisabeth.margareta@gmail.com ${ }^{1}$ opinpanjaitan25@ gmail.com ${ }^{2}$
}

\begin{abstract}
Abstrak
Salah satu media pembelajaran yang banyak dan mudah digunakan dalam Pendidikan Jarak Jauh (PJJ) adalah microsoft powerpoint, yaitu aplikasi microsoft office yang digunakan sebagai media presentasi. Microsoft powerpoint dapat digunakan untuk membuat sebuah video pembelajaran dengan teknik rekam layar (screen recording). Penggunaan video pembelajaran dengan teknik rekam layar (screen recording) ini merupakan pengadaan e-learning dengan berbasis multimedia sebab menggabungkan unsur teks, gambar, audio, dan video. Pelaksanaan kegiatan pengabdian masyarakat ini bertujuan untuk meningkatkan wawasan dan keterampilan guru dalam memilih media pembelajaran yang sesuai selama Pendidikan Jarak Jauh (PJJ). Mitra yang terlibat dalam kegiatan pengabdian kepada masyarakat ini adalah guru-guru di SMK Swasta Yapim Taruna Sei Rotan, dimana kegiatan yang dilakukan adalah pelatihan pembuatan media pembelajaran berupa video pembelajaran dengan teknik rekam layar (screen recording) dengan menggunakan microsoft powerpoint, dan dari hasil pelatihan yang dilaksanakan selama dua hari terlihat guru-guru di SMK Swasta Yapim Taruna Sei Rotan antusias dengan materi yang disajikan dan sudah memahami serta mampu membuat video pembelajaran dengan teknik rekam layar (screen recording).
\end{abstract}

Kata kunci: pembelajaran, powerpoint, video

Abstract

One of the many learning media that is easy to use in Distance Education (PJJ) is Microsoft PowerPoint, which is a Microsoft Office application that is used as a presentation medium. Microsoft powerpoint can be used to create a learning video with screen recording techniques. The use of learning videos with screen recording techniques is a multimedia-based e-learning procurement because it combines elements of text, images, audio, and video. The implementation of this community service activity aims to improve the insight and skills of teachers in choosing appropriate learning media during Distance Education (PJJ). Partners involved in this community service activity are teachers at the Yapim Taruna Sei Rotan Private Vocational School, where the activities carried out are training in making learning media in the form of learning videos with screen recording techniques using Microsoft PowerPoint, and from the results of the training which was held for two days, it was seen that the teachers at the Yapim Taruna Sei Rattan Private Vocational School were enthusiastic about the material presented and already understood and were able to make learning videos using screen recording techniques.

Keywords: learning, powerpoint, video

Copyright (c) 2021 Elisabeth Margareta, Yosefin Panjaitan

$\triangle$ Corresponding author

Address : Jalan Amal Gang Melati-1 No 73C

ISSN 2721-9224 (Media Cetak)

Email : elisabeth.margareta@gmail.com

ISSN 2721- 9216 (Media Online)

DOI : https://doi.org/10.31004/abdidas.v2i5.441 
1141 Media Pembelajaran Screen Recording dari Powerpoint dalam Pembelajaran Jarak Jauh - Elisabeth Margareta, Yosefin Panjaitan

DOI: https://doi.org/10.31004/abdidas.v2i5.441

\section{PENDAHULUAN}

Pandemi COVID-19 menyebabkan perubahan yang cukup signifikan pada semua aspek kehidupan. Salah satu implikasi pandemi COVID-19 adalah berkurangnya interaksi tatap muka atau aturan jaga jarak (physical distancing) termasuk dalam institusi Pendidikan (Leonnard, 2021). Akibatnya, kegiatan pembelajaran di masa pandemi mengalami banyak sekali perubahan, tidak hanya di negara Indonesia bahkan di seluruh dunia.

Dampak yang sangat berpengaruh bagi dunia pendidikan adalah dilakukannya Pendidikan Jarak Jauh (PJJ). Pendidikan Jarak Jauh (PJJ) adalah kegiatan penyelenggaraan pendidikan dari jarak jauh, tidak menggunakan ruang kelas secara fisik. Menurut Undang-undang Perguruan Tinggi nomer 12 tahun 2012, pasal 31 tentang Pendidikan Jarak Jauh (PJJ) menjelaskan bahwa PJJ merupakan proses belajar mengajar yang dilakukan secara jarak jauh melalui penggunaan berbagai media komunikasi. Namun penyelenggaraan PJJ bukanlah hal yang mudah. Banyak sekali hambatan dan tantangan yang dihadapi, tantangan terbesar adalah mengadopsi pembelajaran yang biasa dilakukan di sekolah dipindah menjadi pembelajaran di rumah. Tantangan bukan hanya pada strategi pembelajaran saja namun masalah konsentrasi, perilaku, komunikasi, sensori dan lainnya menjadi tantangan juga dalam pembelajaran di rumah (Kelas Guru Menulis Batch 3, 2020).

Pada pelaksanaannya ada beberapa faktor penting yang harus diperhatikan agar sistem Pendidikan (pembelajaran) jarak jauh dapat berjalan dengan baik, yakni perhatian, percaya diri pendidik, pengalaman, mudah menggunakan peralatan, kreatif menggunakan alat, dan menjalin interaksi dengan peserta didik (Prawiyogi, Anggi Giri, 2020). Penggunaan peralatan disini artinya mahir menggunakan media pembelajaran yang ada.

Salah satu media pembelajaran yang banyak dan mudah digunakan dalam PJJ adalah microsoft powerpoint, yaitu aplikasi microsoft office yang digunakan sebagai media presentasi. Dengan aplikasi seluler powerpoint, kita dapat menampilkan, mengedit, dan menghasilkan presentasi yang mengesankan dimanapun kita berada, dengan pengalaman sentuh intuitif yang didesain untuk telepon dan tablet (Pandapotan Sianipar, 2018). Salah satu contohnya, video pembelajaran rekam layar (screen recording) dengan microsoft powerpoint. Dengan teknik rekam layar (screen recording), materi yang sudah disajikan di powerpoint dapat dijelaskan oleh pengajar sambil pengajar merekamnya. Ketika menjelaskan, pengajar dapat menulis atau membuat coretan-coretan yang dibutuhkan dalam penjelasan materi. Suara yg dikeluarkan pengajar akan terekam begitu juga wajah ketika menjelaskan materi, sehingga meskipun pembelajaran dilakukan dari jarak jauh, pengajar tetap dapat menjelaskan materi dengan maksimal.

Langkah-langkah membuat video pembelajaran dengan teknik rekam layar (screen recording): 1). Buka program komputer powerpoint, 2). Pilih powerpoint yang akan diubah menjadi video, 3). Setelah powerpoint terbuka pilih "file" selanjutnya pilih "export" kemudian 
1142 Media Pembelajaran Screen Recording dari Powerpoint dalam Pembelajaran Jarak Jauh - Elisabeth Margareta, Yosefin Panjaitan

DOI: https://doi.org/10.31004/abdidas.v2i5.441

pilih "create a video", 4). Pada settingan Full HD pilih "standard" dan pada Don't Use Recorded Timings and Narrations pilih "Record Timings and Narrations", 5) Selanjutnya tekan "start recording" lalu mulailah melakukan presentasi, 6). Jika sudah selesai tekan "close" lalu pilih "save as" kemudian "browse" untuk menyimpan file. Isi nama file kemudian save as type ganti menjadi "MPEG-4 Video" kemudian tekan "save". File rekaman tadi akan disimpan dalam bentuk video.

Penggunaan teknik rekam layar ini (screen recording) merupakan pengadaan e-learning dengan berbasis multimedia sebab menggabungkan unsur teks, gambar, audio, video. Keuntungan dan manfaat penyampaian materi dengan konsep multimedia pembelajaran adalah proses pembelajaran lebih menarik, interaktif, waktu mengajar lebih singkat, kualitas belajar siswa meningkat, proses belajar dapat dilakukan kapan saja dan dimana saja, dan sikap belajar siswa dapat ditingkatkan (Studi et al., 2021).

Penulis merasa penggunaan video pembelajaran dengan teknik rekam layar (screen recording) juga akan memberi banyak keuntungan jika diterapkan di SMK Swasta Yapim Taruna Sei Rotan. Oleh karenanya, penulis melakukan pelatihan dengan tujuan meningkatkan wawasan dan keterampilan guru dalam memilih media pembelajaran yang sesuai selama Pendidikan Jarak Jauh (PJJ).

\section{METODE}

Metode yang digunakan dalam kegiatan pengabdian kepada masyarakat ini adalah pelatihan dengan menggunakan metode ceramah dan tanya jawab. Pihak yang terlibat selama kegiatan pelatihan adalah semua guru di SMK Swasta Yapim Taruna Sei Rotan. Pelaksanaan pelatihan dilakukan dua hari, yaitu tanggal 13 dan 14 Januari 2021.

Selama pelatihan, kegiatan-kegiatan yang dilakukan adalah: 1). Presentasi. Dilakukan pada hari pertama pelatihan, dengan menjelaskan secara teori tentang pembelajaran jarak jauh, media pembelajaran, microsoft powerpoint, dan teknik rekam layar (screen recording) dengan menggunakan powerpoint. 2). Tanya jawab. Masih dilakukan pada hari pertama pelatihan, dimana masing-masing guru dapat menyampaikan pertanyaannya untuk didiskusikan bersama. Pada saat yang sama juga antara guru dan penyaji saling berbagi pengalaman mengenai kendala-kendala pembelajaran di lapangan selama pandemi COVID-19. 3) Praktek. Dilakukan pada hari kedua pelatihan, dimana masing-masing guru membuat video pembelajaran dengan teknik rekam layar (screen recording). Sebelumnya masing-masing guru telah diminta untuk mempersiapkan materi yang disusun dalam powerpoint untuk selanjutnya diubah menjadi bentuk video.

Setelah kegiatan pelatihan selesai selanjutnya tim melakukan evaluasi untuk menilai proses awal sampai dengan akhir pelaksanaan kegiatan. Evaluasi dilakukan dengan memberi kesempatan kepada peserta pelatihan untuk memberikan saran dan masukan atas kegiatan yang sudah berlangsung. Tim juga membuka diri untuk memberikan bantuan jika ada hal-hal yang tidak atau kurang dipahami oleh peserta pelatihan. 
1143 Media Pembelajaran Screen Recording dari Powerpoint dalam Pembelajaran Jarak Jauh - Elisabeth Margareta, Yosefin Panjaitan

DOI: https://doi.org/10.31004/abdidas.v2i5.441

\section{HASIL DAN PEMBAHASAN}

Hasil yang diperoleh selama kegiatan pelatihan "Media Pembelajaran Screen Recording dari Powerpoint dalam Pembelajaran Jarak Jauh" adalah:

Selama penyaji memaparkan materi tentang "Media Pembelajaran Screen Recording dari Powerpoint dalam Pembelajaran Jarak Jauh", terlihat guru-guru SMK Swasta Yapim Taruna Sei Rotan serius mendengarkan dan merasa tertarik pada materi yang disajikan.

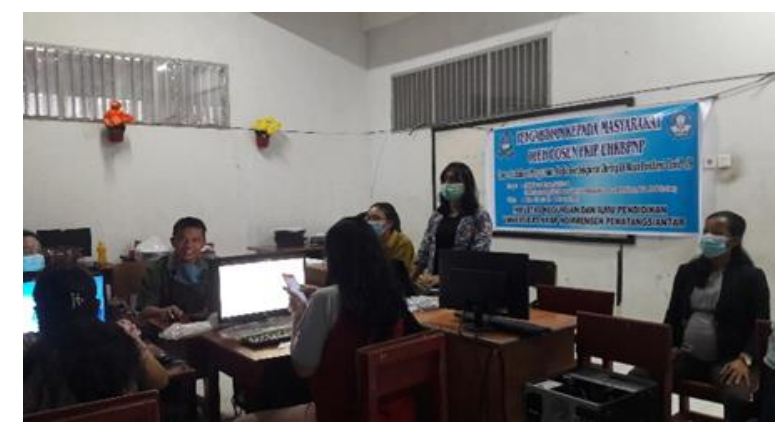

Gambar 1. Pemaparan Materi

Pada sesi tanya jawab, banyak guru yang menunjukkan antusiasmenya dengan bertanya tentang hal-hal menyangkut materi yang memang kurang dipahami. Selanjutnya sesi ini juga menjadi sesi diskusi dan berbagi pengalaman antara guruguru dan penyaji selama melaksanakan kegiatan pembelajaran di lapangan.

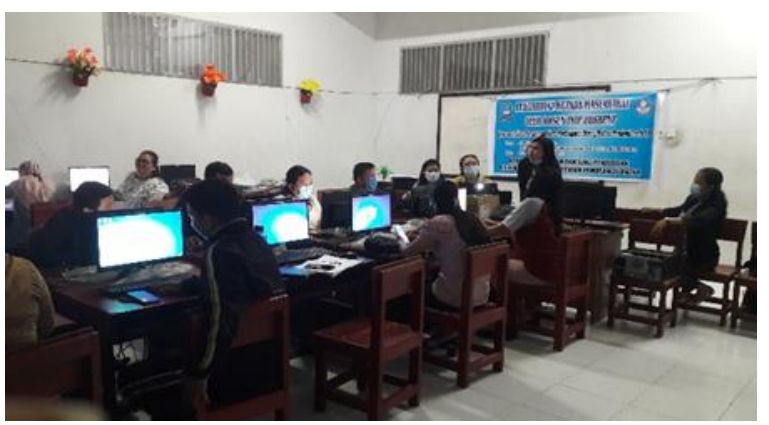

Gambar 2. Tanya Jawab dan Diskusi
Pada sesi terakhir, yaitu di hari kedua, masing-masing guru membuat secara langsung video pembelajaran dengan teknik rekam layar (screen recording) yang dipandu oleh penyaji dan tim. Terlihat guru-guru SMK Swasta Yapim Taruna Sei Rotan sangat antusias dan bersemangat dalam membuat video pembelajaran. Ada guruguru yang membuat video pembelajaran untuk materi yang sudah pernah diajarkan, namun ada juga yang membuat untuk materi yang masih akan diajarkannya. Dari hasil praktek pembuatan video, guru-guru mengakui bahwa pembuatan video pembelajaran dengan teknik rekam layar (screen recording) sangatlah mudah dan sederhana, dan tentunya video pembelajaran tersebut akan sangat bermanfaat dalam pembelajaran jarak jauh.

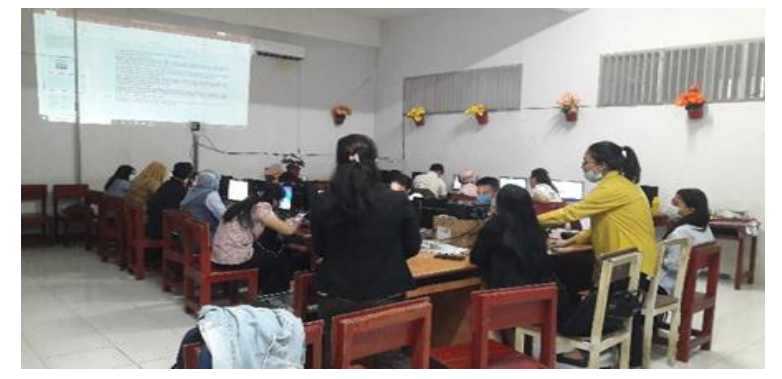

Gambar 3. Pembuatan Video Pembelajaran

\section{SIMPULAN}

Kegiatan pengabdian kepada masyarakat ini bertujuan untuk meningkatkan wawasan dan keterampilan guru dalam memilih media pembelajaran yang sesuai selama Pendidikan Jarak Jauh (PJJ). Media Pembelajaran Screen Recording dari Powerpoint merupakan salah satu solusi dalam pembelajaran yang dilakukan dari jarak jauh selama masa pandemi COVID-19, sebab dengan menggabungkan unsur teks, gambar, audio, dan 
1144 Media Pembelajaran Screen Recording dari Powerpoint dalam Pembelajaran Jarak Jauh - Elisabeth Margareta, Yosefin Panjaitan

DOI: https://doi.org/10.31004/abdidas.v2i5.441

video proses pembelajaran akan lebih menarik dan diharapkan kualitas belajar siswa meningkat karena kegiatan belajar dapat dilakukan kapan saja dan dimana saja. Selama pelatihan berlangsung terlihat para peserta merespon dengan baik dan mampu membuat video pembelajaran dengan teknik rekam layar (screen recording) sehingga diharapkan peserta pelatihan mampu menciptakan suasana belajar yang menarik dan tetap mempertahankan kualitas pembelajaran meskipun dari jarak jauh.

\section{UCAPAN TERIMA KASIH}

Terima kasih diucapkan oleh tim pelaksana pengabdian kepada masyarakat kepada Ibu Tince Sitorus, S.Pd., selaku kepala sekolah SMK Swasta Yapim Taruna Sei Rotan dan peserta pelatihan, yaitu guru-guru SMK Swasta Yapim Taruna Sei Rotan.

\section{DAFTAR PUSTAKA}

Kelas Guru Menulis Batch 3. (2020). Mendidik Di Masa Pandemi. Jejak Publisher.

Leonnard. (2021). Monograf Nonagon Model Kualitas Pembelajaran Jarak Jauh Pendidikan Tinggi Terhadap Kepuasan Mahasiswa Saat Pandemi COVID-19. Deepublish.

Pandapotan Sianipar. (2018). Bekerja Dengan Powerpoint 2016. PT. Elex Media Komputindo.

Prawiyogi, Anggi Giri, D. (2020). Efektifitas Pembelajaran Jarak Jauh Terhadap Pembelajaran Peserta Didik Di SDIT Purwakarta. JPD: Jurnal Pendidikan Dasar, 8.

Studi, P., Teknologi, P., Studi, P., Guru, P., \& Dasar, S. (2021). Jurnal Masyarakat Negeri Rokania Pkm Pemanfaatan E-Learning Berbasis Multimedia Keywords : E-Learning
, Multimedia, Distance Learning . 2(April), 57-63. 